\title{
Peroxiredoxin V: A candidate breast tumor marker of population specificity
}

\author{
AMANY ELAMIN ${ }^{1-3}$, HONGXIA ZHU ${ }^{2}$, A.M. EL HASSAN ${ }^{1}$, NINGZHI XU ${ }^{2}$ and MUNTASIR E. IBRAHIM ${ }^{1}$ \\ ${ }^{1}$ Department of Molecular Biology, Institute of Endemic Diseases, University of Khartoum, Khartoum 11111, Sudan; \\ ${ }^{2}$ Laboratory of Cell and Molecular Biology, Cancer Institute and Hospital, Chinese Academy of Medical Sciences \\ and Peking Union Medical College, Beijing 100021, P.R. China; ${ }^{3}$ Commission for Biotechnology \\ and Genetics Engineering, National Center for Research, Khartoum 11111, Sudan
}

Received August 11, 2012; Accepted January 9, 2013

DOI: $10.3892 / \mathrm{mco} .2013 .91$

\begin{abstract}
Breast and cervical cancers account for approximately $50 \%$ of all types of cancer in Sudanese women. In a previous preliminary proteomic study aimed to identify proteins that were differentially expressed between tumors and control tissues $(n=24)$, we identified peroxiredoxin $V$ (PrdxV) as a candidate tumor marker. Peroxiredoxins (Prdxs) are a family of multifunctional proteins that are involved in the cell protection against oxidative stress, modulation of intracellular signaling, and regulation of cell proliferation. Knockout animal models suggest that the regulation of these proteins may be a novel target for therapeutic interventions. A total of 91 tumors and 79 normal breast tissues obtained from a panel of 106 Sudanese breast cancer patients, as well as 31 paired tissue samples (tumors and controls) from Chinese cancer patients were included in this study. Tissue sections were examined using immunohistochemistry (IHC) for PrdxI, V and VI antibodies. The PrdxV mRNA pattern of expression was also investigated using in situ hybridization (ISH). The overall expression of the same Prdx family members was also examined in a panel of Chinese breast carcinoma and control samples. Statistical comparisons were performed between Prxds antibodies, and between available demographic and pathological parameters. The studied Prdxs were found to be overexpressed in both Sudanese and Chinese breast cancer and control samples. PrdxV was the
\end{abstract}

Correspondence to: Professor Muntasir E. Ibrahim, Department of Molecular Biology, Institute of Endemic Diseases, University of Khartoum, ElQasser St., University of Khartoum Medical Campus, P.O. Box 102, Khartoum 11111, Sudan

E-mail: mibrahim@iend.org

Abbreviations: Prdxs, peroxiredoxins; $\operatorname{PrdxV}$, peroxiredoxin V; IEND, Institute of Endemic Diseases; FFPE, formalin-fixed paraffin-embedded; IHC, immunohistochemistry; ISH, in situ hybridization

Key words: peroxiredoxins, breast cancer, tumor marker, post-translational modifications only member of the Prdxs family to be significantly downregulated in Sudanese tumor samples, with only a few cases being immunoreactive for PrdxV (11\%). Significant elevation was demonstrated between tumors and controls at both the protein (using IHC) $(\mathrm{P}=0.000)$ and mRNA (using ISH) $(\mathrm{P}=0.044)$ levels. However, the finding was more apparent and statistically significant at the protein level, suggesting the presence of post-translational modification. These findings suggest that $\operatorname{PrdxV}$ is a tumor marker of population specificity. However, more studies are needed to investigate the applicability of PrdxV as a marker in Sudanese breast cancer patients and its potential implications in therapy.

\section{Introduction}

Peroxiredoxins (Prdxs) are a family of small proteins that catalyze the reduction of peroxides using their conserved Cys residues as catalytical centers (1). Six Prdx isoforms have been found in mammalian cells, but they are non-redundant antioxidant proteins (2). The six isoforms of human Prdxs are located on chromosomes 1, 4, 8, 19 and X, with both PrdxIII and V located on chromosome 19 (3). The regulation of Prdxs has been investigated in various types of cancer. The expression of Prdxs, especially III, IV and V, has been found to be increased in breast malignancy, suggesting the induction of the expression of Prdxs as a response to the increased production of reactive oxygen species (ROS) in carcinoma tissues $(4,5)$. Moreover, some members of Prdxs are thought to be cancer cell biomarkers (3). The knockdown of members of the Prdx family was previously shown to lead to clear distortion of cell signaling and tumor formation (6-9).

The aim of this study was to validate a previous finding according to which PrdxV constitutes a tumor marker of the breast in Sudanese patients (unpublished data), by investigating the expression pattern of a panel of Prdxs family members in Sudanese and Chinese patients.

\section{Materials and methods}

Patients. A panel of 106 Sudanese breast cancer patients (91 tumors and 79 normal breast tissues, of which 59 were tumor control pairs) were included in this case-control 
hospital-based study (Table I). The tissue samples were obtained from the El-Zahrawi Medical Center in Khartoum (Sudan) and the Institute of Endemic Diseases (IEND; University of Khartoum, Khartoum, Sudan) Tumor Bank. This study was approved by the Ethics Committee of the IEND and all patients provided informed consent. The samples were preserved in the form of formalin-fixed paraffin-embedded (FFPE) tissue blocks.

Chinese breast cancer patients. A panel of 31 paired (tumors and controls) tissue samples from Chinese breast cancer patients (invasive ductal carcinoma) in the form of tissue arrays (Shanghai Outdo Biotech Co., Ltd., Shangai, China) were also included in the study.

Immunohistochemistry (IHC). Both Sudanese and Chinese breast cancer tissue sections and controls were examined immunohistochemically, for the following Prdxs antibodies: PrdxI, V and VI (Table II). IHC was performed using the 2-step plus Poly-HRP anti-mouse/rabbit IgG detection system (biotin-free, anti-mouse/rabbit multivalent) kit (Golden Bridge International, Everett, WA, USA).

In situ hybridization (ISH). To design the PrdxV probe, PCR was performed using the modified primers $(10,11)$ by the addition of the EcoRI and BamHI restriction sites (italics) (Invitrogen, Carlsbad, CA, USA): Prdx5, F, 5'-CGGAATTCAT GGCCCCAATCAAGGTGGGAGAT-3' and R, 5'-CGGGAT CCCAGAGCTGTGAGATGATATTGG-3'.

The purified $\operatorname{PrdxV}$ gene was cloned using pcDNA $^{\text {TM } 3.1 / m y c-H i s(-) B ~ M C S ~ p l a s m i d ~(I n v i t r o g e n) . ~}$ Plasmids were prepared using standard methods, as described in a previous study (12). RNA probes were labeled with digoxigenin (DIG) using the DIG RNA labeling kit according to the manufacturer's instructions (SP6/T7; Roche Diagnostics, Indianapolis, IN, USA). The optimal concentration of $100 \mathrm{pg} / \mu 1$ was chosen using DIG wash and block buffer according to the manufacturer's instructions (Roche Diagnostics). ISH was performed as described by Breitschopf et al (13). The labeled antisense RNA probe was diluted $(100 \mathrm{pg} / \mu \mathrm{l})$ in hybridization buffer (12) and a labeled sense RNA probe was used as the control. The sections were incubated with alkaline-phosphatase-conjugated anti-DIG antibody, incubated with NBT/BCIP color reagent (Roche Diagnostics) overnight, and mounted with a water-soluble mounting medium.

Statistical analysis. The slides were independently examined by two experienced observers who were blinded to the initial results of the other observer. Immunoreactivity was allocated a score based on the percentage of positive tumor cells over total tumor cells ranging from 0 to $100 \%$ and on staining intensity (0, negative; 1 , weak; 2 , moderate; and 3 , strong). Prdxs immunostaining scores were as follows: 0 , negative or weak staining; and 1, moderate or strong staining. Clinicopathological parameters for the Sudanese patients were sub-classified as described in Table I. Descriptive statistics were calculated using the SPSS 11.5 statistical program. $\mathrm{P}<0.05$ (two-sided test) was considered to indicate a statistically significant difference.
Table I. Patient clinicopathological characteristics of the Sudanese patients.

\begin{tabular}{|c|c|}
\hline Clinicopathological characteristics & No. $(\%)$ \\
\hline Sample no. & $106(100)$ \\
\hline \multicolumn{2}{|l|}{ Histological type } \\
\hline Ductal carcinoma in situ (DCIS) & $2(2)$ \\
\hline Invasive ductal carcinoma (NOS) & $60(57)$ \\
\hline Mixed ductal carcinoma (DCIS+NOS) & $18(27)$ \\
\hline Lobular carcinoma & $2(2)$ \\
\hline Others (e.g., papillary and medullary) & $13(12)$ \\
\hline Mixed types & $5(5)$ \\
\hline Missing data & $5(5)$ \\
\hline Total & 105 \\
\hline Mean age (years) & $46.24(24-79)$ \\
\hline \multicolumn{2}{|l|}{ Gender } \\
\hline Female & $101(95.3)$ \\
\hline Male & $2(1.9)$ \\
\hline Missed data & $2(1.9)$ \\
\hline \multicolumn{2}{|l|}{ Ethnicity } \\
\hline Afro-Asiatic & $41(39)$ \\
\hline Nilo-Saharan & $19(18)$ \\
\hline Niger-Kordofanian & $1(1)$ \\
\hline Unknown & $44(42)$ \\
\hline \multicolumn{2}{|l|}{ Nodal metastasis } \\
\hline Presence & $37(35.2)$ \\
\hline Absence & $19(18.1)$ \\
\hline Unknown & $46(46.7)$ \\
\hline \multicolumn{2}{|l|}{ Tumor size (cm) } \\
\hline from 0 to $<2$ & $6(5.7)$ \\
\hline from 1 to $\geq 2$ & $70(66.04)$ \\
\hline Unknown & $30(28.3)$ \\
\hline
\end{tabular}

DCIS, ductal carcinoma in situ; NOS, invasive carcinoma.

\section{Results}

Immunohistochemistry. The PrdxV level of expression in samples from Sudanese patients (a panel of 77 tumor and 68 control samples of which 51 were paired samples) was notably low compared to previously published studies $(4,5)$. Only 9/77 (11.7\%) breast cancer tissue samples were immunoreactive for the PrdxV antibody, whereas $88.3 \%$ of the samples were negative (Fig. 1). In the control samples, 29/68 (42.6\%) were positive for the PrdxV antibody (Fig. 2), indicating a significant difference between tumors and non-malignant controls $(\mathrm{P}=0.000)$ (Figs. 3 and 4; Table III). In Chinese samples, PrdxV was found to be predominantly overexpressed in both tumor and control samples with 24/30 (80\%) tumor samples, and 26/31 (83.9\%) control samples being immunoreactive for the PrdxV antibody (Table III).

Unlike the Sudanese samples, the difference between PrdxV expression in tumors and controls in Chinese breast cancer patients was found to be insignificant $(\mathrm{P}=0.749)$. 
Table II. Antibodies used in this study.

\begin{tabular}{lclll}
\hline Protein & Clone & \multicolumn{1}{c}{ Source } & Dilution & Origin \\
\hline PrdxV & (FL-214) & Santa Cruz Biotechnology, Inc. (Santa Cruz, CA, USA) & $1: 500$ & Rabbit polyclonal \\
PrdxI & $($ ab59538) & Abcam (Cambridge, MA, USA) & $1: 1,000$ & Rabbit polyclonal \\
PrdxVI & $($ ab59543) & Abcam & $1: 1,000$ & Rabbit polyclonal \\
PARP & 9542 & Cell Signaling Technology, Inc. (Beverly, MA, USA) & $1: 1,000$ & Rabbit polyclonal \\
C-Myc & $9 \mathrm{E} 10$ & BD Biosciences (Franklin Lakes, NJ, USA) & $1: 1,000$ & Mouse polyclonal \\
\hline
\end{tabular}

PARP, poly (ADP-ribose) polymerase.
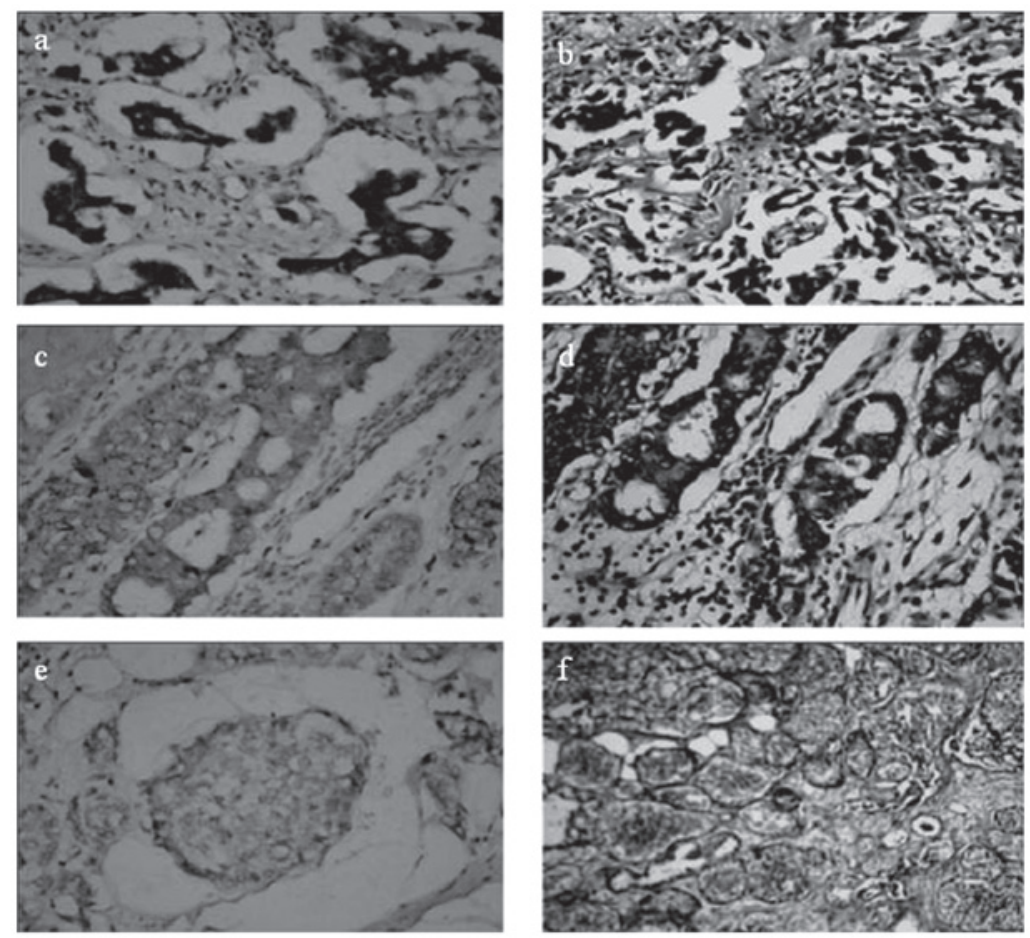

Figure 1. PrdxV expression in breast carcinoma. (a) Strong positive tumor (IHC); (b) same focus (H\&E); (c) stained positive tumor (IHC); (d) same focus (H\&E); (e) negative tumor (IHC); (f) same sample (H\&E). IHC, immunohistochemistry; H\&E, hematoxylin and eosin.
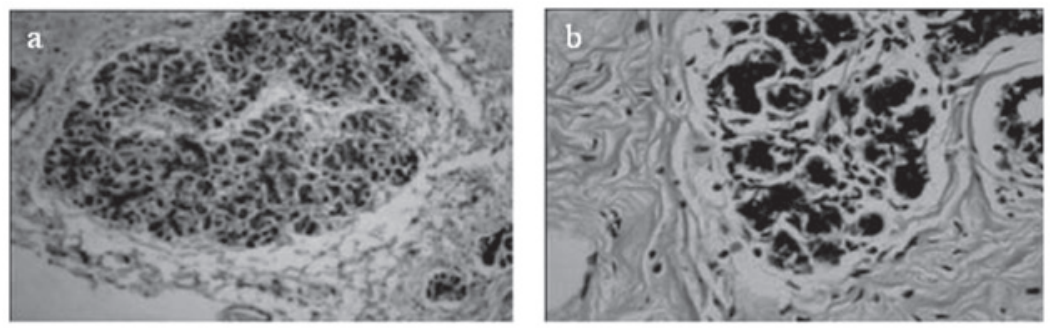

Figure 2. PrdxV expression in normal breast tissue (control). (a) Strong positive control (IHC); (b) same focus (H\&E). IHC, immunohistochemistry; H\&E, hematoxylin and eosin.

Similarly no correlation was detected between PrdxV expression and the available pathological parameters, such as lymphatic invasion $(\mathrm{P}=1.000)$, tumor size $(\mathrm{P}=1.000)$ and grade $(\mathrm{P}=1.000)$. In addition, there was no correlation with other demographic parameters, such as age $(\mathrm{P}=0.412)$, gender $(\mathrm{P}=0.108)$, ethnicity $(\mathrm{P}=0.682)$ and patients' geographical origin $(\mathrm{P}=0.686)$ (Table IV).
Expression of PrdxI and VI protein was also examined immunohistochemically in Sudanese and Chinese tissue samples and was found to be overexpressed in both tumors and controls in Sudanese and Chinese breast tissue samples (Tables III and VI, respectively). The difference between PrdxI and VI protein expression in tumors and controls in Sudanese and Chinese samples was statistically examined 

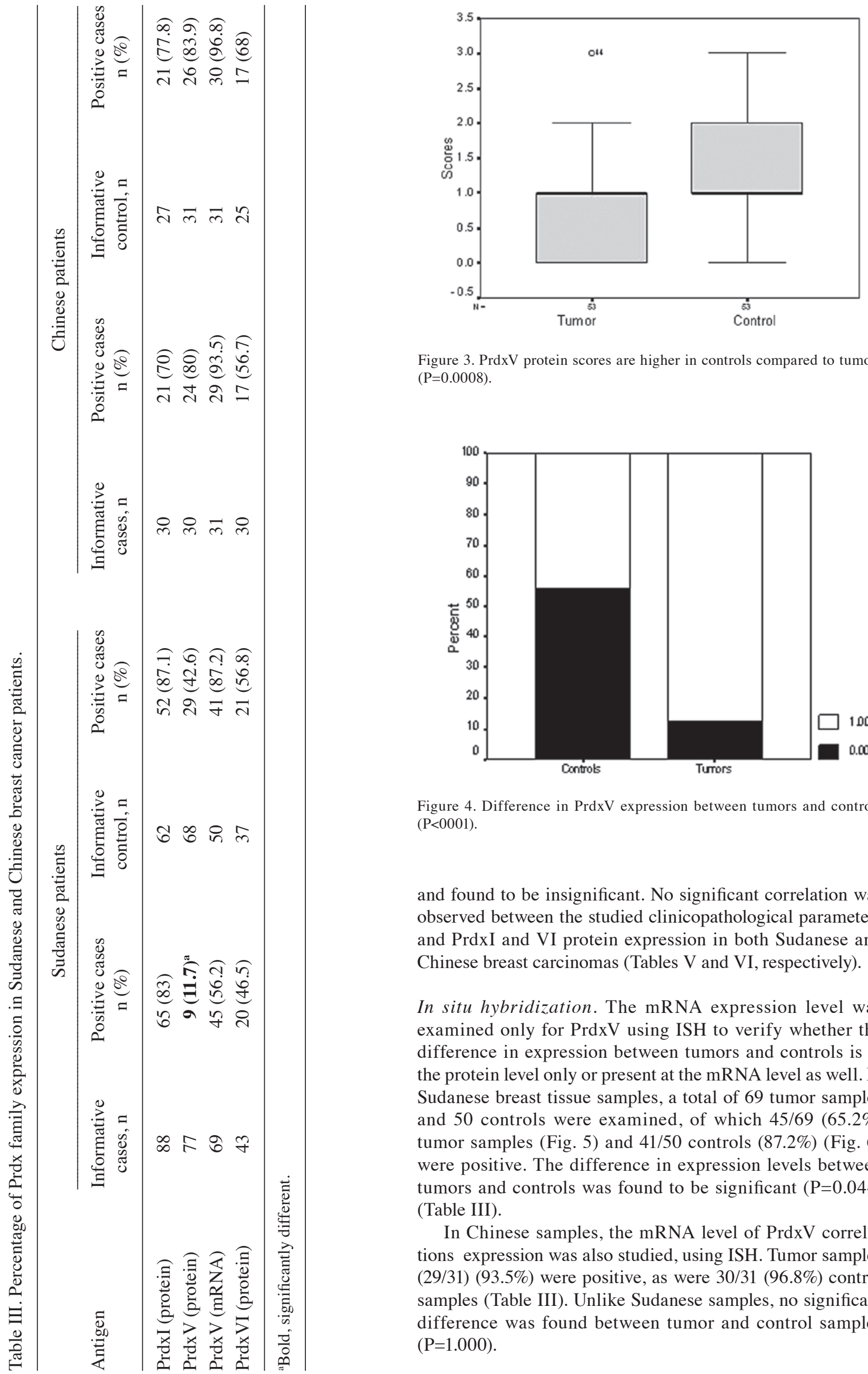

Figure 3. PrdxV protein scores are higher in controls compared to tumors $(\mathrm{P}=0.0008)$.

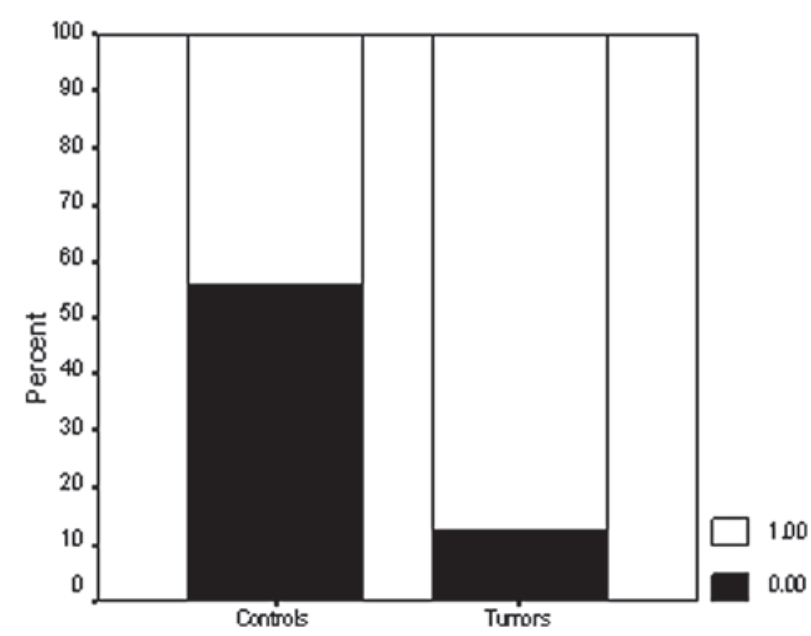

Figure 4. Difference in PrdxV expression between tumors and controls $(\mathrm{P}<0001)$.

and found to be insignificant. No significant correlation was observed between the studied clinicopathological parameters and PrdxI and VI protein expression in both Sudanese and Chinese breast carcinomas (Tables V and VI, respectively).

In situ hybridization. The mRNA expression level was examined only for PrdxV using ISH to verify whether the difference in expression between tumors and controls is at the protein level only or present at the mRNA level as well. In Sudanese breast tissue samples, a total of 69 tumor samples and 50 controls were examined, of which $45 / 69$ (65.2\%) tumor samples (Fig. 5) and 41/50 controls (87.2\%) (Fig. 6) were positive. The difference in expression levels between tumors and controls was found to be significant $(\mathrm{P}=0.044)$ (Table III).

In Chinese samples, the mRNA level of PrdxV correlations expression was also studied, using ISH. Tumor samples (29/31) (93.5\%) were positive, as were 30/31 (96.8\%) control samples (Table III). Unlike Sudanese samples, no significant difference was found between tumor and control samples $(\mathrm{P}=1.000)$. 
Table IV. Correlations between PrdxV pathological characteristics and other studied Prdxs (Sudanese samples).

\begin{tabular}{lccc}
\hline & Negative & Positive & \\
Characteristics & $\mathrm{n}(\%)$ & $\mathrm{n}(\%)$ & P-value \\
\hline
\end{tabular}

Age (years)
$\leq 46$
$>46$
Total

Gender

Female
Male
Total

Lymphatic invasion

Negative
Positive
Total

Tumor size $(\mathrm{cm})$

from 0 to $<2$
from 1 to $\geq 2$
Total
Grade
Low
High
Total
Ethnicity
Nilo-Saharan
Afro-Asiatic
Niger-Kordofanian
Total

Patients' geographical origin

North
East
West
Center
South
Breast cancer type
NOS
DCIS
LCIS
NOS+DCIS
Other types
Mixed types
Total
ISH

$\begin{array}{cl}25(56.8) & 4(80) \\ 1(2.3) & 0(0) \\ 11(25) & 0(0) \\ 5(11.4) & 1(20) \\ 2(4.5) & 0(0)\end{array}$

$\begin{array}{cll}5(9.4) & 0(0) & 1.000(\mathrm{~F}) \\ 48(90.6) & 7(100) & \\ 53(100) & 7(100)\end{array}$

$1(2.4) \quad 0(0) \quad 1.000(\mathrm{~F})$

$40(97.6) \quad 6(100)$

$41(100) \quad 6(100)$

$\begin{array}{cll}15(35.7) & 1(20) & 0.682(\mathrm{~F}) \\ 26(61.9) & 4(80) & \\ 1(2.4) & 0(0) & \\ 42(100) & 5(100)\end{array}$

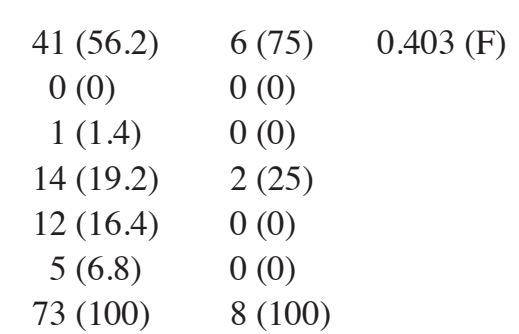

SH

$\begin{array}{lccc}\text { Negative } & 22(95.7) & 38(86.4) & 0.000 \text { (Chi) } \\ \text { Positive } & 1(4.3) & 6(13.6) & \\ \text { Total } & 23(100) & 44(100) & \end{array}$

PrdxI

Negative

16 (23.2)

$0(0)$

Positive

$53(76.8) \quad 5(100)$

Total
Table IV. Continued.

\begin{tabular}{lccc}
\hline Characteristics & $\begin{array}{c}\text { Negative } \\
\mathrm{n}(\%)\end{array}$ & $\begin{array}{c}\text { Positive } \\
\mathrm{n}(\%)\end{array}$ & P-value \\
\hline PrdxVI & & & \\
Negative & $20(55.6)$ & $1(33.3)$ & 0.000 (Chi) \\
Positive & $16(44.4)$ & $2(66.7)$ & \\
Total & $36(100)$ & $3(100)$ & \\
\hline
\end{tabular}

F, Fisher's exact test; Chi, Chi-square test; NOS, invasive carcinoma; DCIS, ductal carcinoma in situ; LCIS, lobular carcinoma in situ; ISH, in situ hybridization; PrdxI, peroxiredoxin I; PrdxVI, peroxiredoxin VI.

\section{Discussion}

In the present study, a panel of Sudanese breast cancer tissue samples and healthy controls were investigated. Tissue sections were examined immunohistochemically to assess the PrdxV protein level of expression. The PrdxV mRNA expression was also evaluated using ISH. The bold score of PrdxV expression is representative of the finding of a preliminary proteomic study suggesting that PrdxV is differentially expressed in Sudanese breast cancer tissues as compared to healthy controls (unpublished data) (Table III). Various Prdx family members (PrdxI and VI) were also examined to ensure the specificity of $\operatorname{PrdxV}$, mainly as a tumor marker among other family members. Additionally, to determine whether the PrdxV mode of expression is universal or limited to Sudanese breast cancer patients, the same experimental design was implemented in a panel of Chinese breast carcinoma samples and controls, and the two populations were compared.

Of the various Prdx family members, PrdxV was the only one that was significantly downregulated in tumor samples obtained from Sudanese breast cancer patients. At the protein level, only a few tumor samples were immunoreactive for PrdxV, only 9/77 (11.7\%) were positive $(\mathrm{P}<0.0001)$, while $29 / 68(47 \%)$ of the controls were immunoreactive $(\mathrm{P}=0.225)$. Based on these results, it appears that the PrdxV protein is not abundantly in present Sudanese neoplastic breast tissues, likely due to the fact that $\operatorname{PrdxV}$ may have a different role in these cells. This finding is contradictory to previous findings by Karihtala et al (5), where $79.8 \%$ of the studied cases were positive for PrdxV antibody, suggesting that a larger set of controls $(n=68)$ was investigated in this study compared to that by Karihtala et al (5) where only three controls were examined immunohistochemically. The finding that PrdxV is downregulated in Sudanese breast cancer samples is also inconsistent with results obtained in a panel of Chinese breast carcinoma samples and controls, where PrdxV protein was found to be overexpressed in both tumors (80\%) and controls (83.9\%). This finding is also inconsistent with various Prdx family members examined (PrdxI and VI) in both Sudanese and Chinese tumor tissues and controls (Table III), suggesting the expression discrepancy to be restricted to the PrdxV protein of Sudanese patients only. 
Table V. Correlations of PrdxI with pathological characteristics (Sudanese samples).

\begin{tabular}{|c|c|c|c|}
\hline Characteristics & $\begin{array}{c}\text { Negative } \\
\mathrm{n}(\%)\end{array}$ & $\begin{array}{l}\text { Positive } \\
\mathrm{n}(\%)\end{array}$ & $\mathrm{P}$-value \\
\hline \multicolumn{4}{|l|}{ Age (years) } \\
\hline$\leq 46$ & $43(65.2)$ & $3(42.9)$ & \multirow[t]{3}{*}{$0.412(\mathrm{~F})$} \\
\hline$>46$ & $23(34.8)$ & $4(57.1)$ & \\
\hline Total & $66(100)$ & $7(100)$ & \\
\hline \multicolumn{4}{|l|}{ Gender } \\
\hline Female & $74(100)$ & $8(88.9)$ & \multirow[t]{3}{*}{$0.108(\mathrm{~F})$} \\
\hline Male & $0(0)$ & $1(11.1)$ & \\
\hline Total & $74(100)$ & $9(100)$ & \\
\hline \multicolumn{4}{|l|}{ Lymphatic invasion } \\
\hline Negative & $13(33.3)$ & $2(40)$ & \multirow[t]{3}{*}{$1.000(\mathrm{~F})$} \\
\hline Positive & $26(66.7)$ & $3(60)$ & \\
\hline Total & $39(100)$ & $5(100)$ & \\
\hline \multicolumn{4}{|l|}{ Tumor size (cm) } \\
\hline from 0 to $<2$ & $5(9.4)$ & $0(0)$ & \multirow[t]{3}{*}{$1.000(\mathrm{~F})$} \\
\hline from 1 to $\geq 2$ & $48(90.6)$ & 7 (100) & \\
\hline Total & $53(100)$ & $7(100)$ & \\
\hline \multicolumn{4}{|l|}{ Grade } \\
\hline Low & $1(2.4)$ & $0(0)$ & \multirow[t]{3}{*}{$1.000(\mathrm{~F})$} \\
\hline High & $40(97.6)$ & $6(100)$ & \\
\hline Total & $41(100)$ & $6(100)$ & \\
\hline \multicolumn{4}{|l|}{ Breast cancer type } \\
\hline NOS & $8(50)$ & $37(59.7)$ & \multirow[t]{7}{*}{$0.056(\mathrm{~F})$} \\
\hline DCIS & $0(0)$ & $0(0)$ & \\
\hline LCIS & $0(0)$ & $1(1.6)$ & \\
\hline NOS+DCIS & $2(12.5)$ & $14(22.6)$ & \\
\hline Other types & $6(37.5)$ & $5(8.1)$ & \\
\hline Mixed types & $0(6.8)$ & $5(8.1)$ & \\
\hline Total & $16(100)$ & $62(100)$ & \\
\hline \multicolumn{4}{|l|}{ Ethnicity } \\
\hline Nilo-Saharan & $15(35.7)$ & $1(20)$ & \multirow[t]{4}{*}{$0.682(\mathrm{~F})$} \\
\hline Afro-Asiatic & $26(61.9)$ & $4(80)$ & \\
\hline Niger-Kordofanian & $1(2.4)$ & $0(0)$ & \\
\hline Total & $42(100)$ & $5(100)$ & \\
\hline \multicolumn{4}{|l|}{$\begin{array}{l}\text { Patients' geographical } \\
\text { origin }\end{array}$} \\
\hline North & $25(56.8)$ & $4(80)$ & \multirow[t]{6}{*}{$0.686(\mathrm{~F})$} \\
\hline East & $1(2.3)$ & $0(0)$ & \\
\hline West & $11(25)$ & $0(0)$ & \\
\hline Center & $5(11.4)$ & $1(20)$ & \\
\hline South & $2(4.5)$ & $0(0)$ & \\
\hline Total & $44(100)$ & $5(100)$ & \\
\hline
\end{tabular}

F, Fisher's exact test; NOS, invasive carcinoma; DCIS, ductal carcinoma in situ; LCIS, lobular carcinoma in situ.

To investigate whether $\operatorname{Prdx} V$ gene expression loss, assessed by IHC, occurs at the protein level or at an earlier stage, such as at the transcription level, the mRNA mode of
Table VI. Correlations of Prdx VI with pathological characteristics (Sudanese samples).

\begin{tabular}{|c|c|c|c|}
\hline Characteristics & $\begin{array}{c}\text { Negative } \\
\mathrm{n}(\%)\end{array}$ & $\begin{array}{c}\text { Positive } \\
\mathrm{n}(\%)\end{array}$ & P-value \\
\hline \multicolumn{4}{|l|}{ Age (years) } \\
\hline$\leq 46$ & $43(65.2)$ & $3(42.9)$ & $0.412(\mathrm{~F})$ \\
\hline$>46$ & $23(34.8)$ & $4(57.1)$ & \\
\hline Total & $66(100)$ & $7(100)$ & \\
\hline \multicolumn{4}{|l|}{ Gender } \\
\hline Female & $74(100)$ & $8(88.9)$ & $0.108(\mathrm{~F})$ \\
\hline Male & $0(0)$ & $1(11.1)$ & \\
\hline Total & $74(100)$ & $9(100)$ & \\
\hline \multicolumn{4}{|l|}{ Lymphatic invasion } \\
\hline Negative & $13(33.3)$ & $2(40)$ & $1.000(\mathrm{~F})$ \\
\hline Positive & $26(66.7)$ & $3(60)$ & \\
\hline Total & $39(100)$ & $5(100)$ & \\
\hline \multicolumn{4}{|l|}{ Tumor size (cm) } \\
\hline from 0 to $<2$ & $5(9.4)$ & $0(0)$ & $1.000(\mathrm{~F})$ \\
\hline from 1 to $\geq 2$ & $48(90.6)$ & $7(100)$ & \\
\hline Total & $53(100)$ & $7(100)$ & \\
\hline \multicolumn{4}{|l|}{ Grade } \\
\hline Low & $1(2.4)$ & $0(0)$ & $1.000(\mathrm{~F})$ \\
\hline High & $40(97.6)$ & $6(100)$ & \\
\hline Total & $41(100)$ & $6(100)$ & \\
\hline \multicolumn{4}{|l|}{ Breast cancer type } \\
\hline NOS & $13(56.5)$ & $10(52.6)$ & $0.056(\mathrm{~F})$ \\
\hline DCIS & $0(0)$ & $0(0)$ & \\
\hline LCIS & $0(0)$ & $0(0)$ & \\
\hline NOS+DCIS & $5(21.7)$ & $4(21.1)$ & \\
\hline Other types & $3(13)$ & $4(21.1)$ & \\
\hline Mixed types & $2(8.7)$ & $1(5.3)$ & \\
\hline Total & $23(100)$ & $19(100)$ & \\
\hline \multicolumn{4}{|l|}{ Ethnicity } \\
\hline Nilo-Saharan & $15(35.7)$ & $1(20)$ & $0.682(\mathrm{~F})$ \\
\hline Afro-Asiatic & $26(61.9)$ & $4(80)$ & \\
\hline Niger-Kordofanian & $1(2.4)$ & $0(0)$ & \\
\hline Total & $42(100)$ & $5(100)$ & \\
\hline \multicolumn{4}{|l|}{$\begin{array}{l}\text { Patients' geographical } \\
\text { origin }\end{array}$} \\
\hline North & $25(56.8)$ & $4(80)$ & $0.960(\mathrm{~F})$ \\
\hline East & $1(2.3)$ & $0(0)$ & \\
\hline West & $11(25)$ & $0(0)$ & \\
\hline Center & $5(11.4)$ & $1(20)$ & \\
\hline South & $2(4.5)$ & $0(0)$ & \\
\hline Total & $44(100)$ & $5(100)$ & \\
\hline
\end{tabular}

F, Fisher's exact test; NOS, invasive carcinoma; DCIS, ductal carcinoma in situ; LCIS, lobular carcinoma in situ.

expression was investigated using ISH and was found to be overexpressed in both tumors and controls, with $56.2 \%$ of the studied tumors being immunoreactive to $\operatorname{PrdxV}$ antibody 

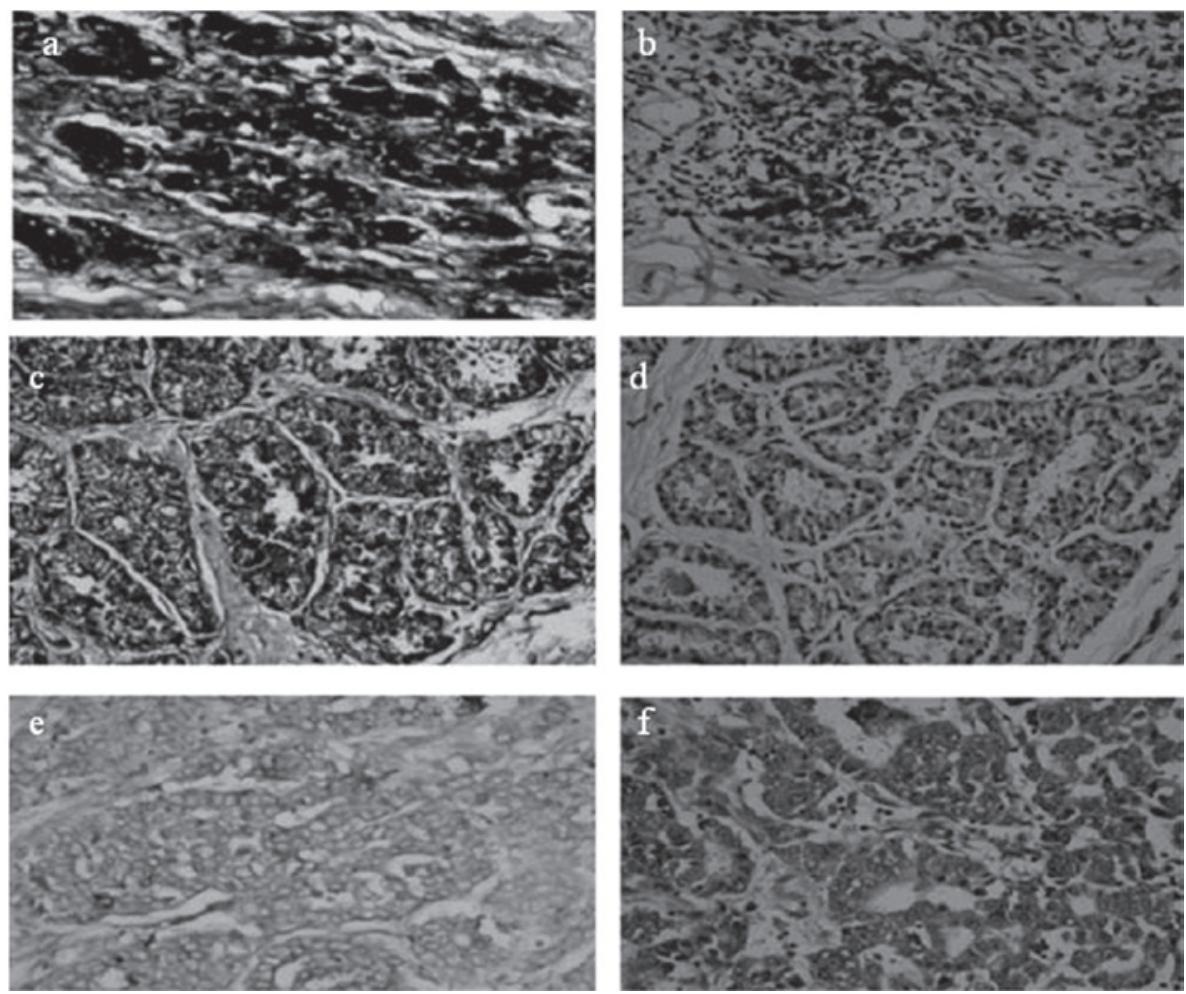

Figure 5. PrdxV expression in breast carcinoma. (a) Strong positive tumor (ISH); (b) same focus (H\&E); (c) medium positive tumor (ISH); (d) same focus (H\&E); (e) negative tumor (ISH), (f) same focus (H\&E). ISH, in situ hybridization; H\&E, hematoxylin and eosin.
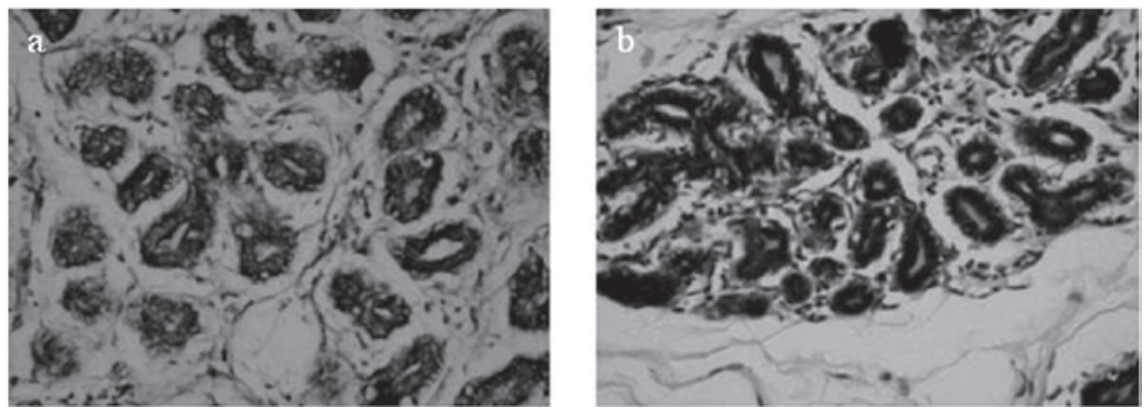

Figure 6. PrdxV expression in breast normal tissue (control). (a) Faint positive control (ISH); (b) same focus (H\&E). ISH, in situ hybridization; H\&E, hematoxylin and eosin.

( $\mathrm{P}=0.011)$, and $87.2 \%$ of controls being positive $(\mathrm{P}<0.0001)$. PrdxV mRNA expression was also found to be significantly different between tumors and controls $(\mathrm{P}=0.044)$. In the Chinese cases, PrdxV mRNA was found to be overexpressed in both tumors (93.5\%) and controls (96.8\%), with no significant difference being identified in the expression between tumors and controls. ISH results assessing PrdxV mRNA expression levels in this study were in accordance with previous findings (14) assessing mRNA expression levels for all members of the Prdx and thioredoxin (Trx) families. PrdxV mRNA expression levels were found to be upregulated in breast cancer compared to normal breast tissues (14), and were in accordance with the immunohistochemical findings of $\operatorname{PrdxV}$ in Sudanese samples regarding the difference between tumors and controls. However, the difference was more apparent and statistically significant at the protein level, suggesting a post-translational modification. The regulation of Prdx activity occurs at the gene expression level and by post-translational protein modification and has received considerable attention (15-18). An example of gene expression loss and its effect on tumorigenesis is the loss of E-cadherin expression in lobular carcinomas of the breast (19-21).

The PrdxV protein expression loss in Sudanese breast cancer patients may have two consequences of antagonistic nature during tumorigenesis. The first one is the expected poor prognosis of tumors due to loss of PrdxV function which protects tissues from harmful ROS, which are usually considered to have carcinogenic potential and promote invasiveness $(22,23)$. Prdx isoforms are non-redundant antioxidant proteins (2), since previous studies have shown that the knockdown of members of the Prdx family led to the distortion of cell signaling and tumor formation $(6,7,9)$. Therefore, the downregulation of $\operatorname{PrdxV}$ in Sudanese breast cancer patients is expected to yield cells more prone to oxidative stress and its 
accompanying DNA damage, leading to a poorer prognosis of Sudanese breast cancer patients. The second consequence of the PrdxV protein expression loss in Sudanese breast cancer patients is correlated with the absence of the PrdxV anti-apoptotic function, which is expected to induce breast cancer tissue sensitivity to chemo- and radiotherapies. PrdxV has been previously shown to have a protective role against oxidative stress and to lead to apoptosis (24-26).

Clinicopathological data were obtained for most of the studied cases, correlations were examined comparing the Prxds examined in the present study to each other, to available demographic data including age, gender and ethnicity, as well as to the available pathological parameters such as histological types, nodal metastasis and tumor size, which are also known prognostic markers of breast cancer. No statistically significant correlation was identified, whereas Karihtala et al (5) detected significant associations between PrdxV overexpression and larger tumor size, lymph node metastases, and poor differentiation of tumors. The finding in this study may not constitute a conclusion regarding the correlation between PrdxV expression and pathological parameters, since those parameters are not normally distributed, as most breast cancer patients present in Sudan, present with large tumors, high grades, and positive metastatic nodes in the majority of cases. This observation has been previously noted in Sudanese $(27,28)$, as well as in African breast cancer patients (29).

The most important finding in this study is the marked downregulation of PrdxV in Sudanese breast cancer patients, suggesting that the molecule be regarded as a tumor marker. Numerous markers were previously identified with only a limited number of these markers being accepted for routine clinical use, such as HER2, ER and PR (30). Although this study suggests that PrdxV be regarded as a tumor marker of population specificity, it should be taken into consideration that breast cancer in individual patients may differ widely from one another in natural history and response to treatment (31). Population differences in breast cancer characteristics were previously described in terms of pathological parameters $(27,31,32)$, and in terms of the identification of mutations, intronic variant sequences and unclassified variants, as well as variated copy numbers, reporting a role in breast cancer susceptibility that remains to be clarified. For instance, mutations in the predisposition genes $B R C A 1$ and $B R C A 2$, known to be associated with hereditary breast cancer, were studied in different populations such as Sudanese $(33,34)$, Tunisian (35), Indian (36) and Slovak (37), where population-specific genetic disorders were observed. Similarly, the $M s p l$ polymorphism in the 3'-non-coding region of the CYPIAl gene was associated with breast cancer in African-American but not in Caucasian women (38).

In conclusion, the downregulation of PrdxV in Sudanese breast cancer patients is suggested as a tumor marker of population specificity. However, additional studies are needed to investigate the applicability of PrdxV as a tumor marker in Sudanese breast cancer patients complementing, but not replacing, the traditional diagnostic and prognostic markers. Additionally, further investigation is required to determine ways of incorporating this suggested marker into routine radio- and/or chemotherapy.

\section{Acknowledgements}

This study was funded by the Third World Organization for Women in Science (TWOWS) and the Swedish International Development Cooperation Agency (SIDA).

\section{References}

1. Greenberg JT and Demple B: Overproduction of peroxidescavenging enzymes in Escherichia coli suppresses spontaneous mutagenesis and sensitivity to redox-cycling agents in oxyR-mutants. Embo J 7: 2611-2617, 1988.

2. Dietz KJ: The dual function of plant peroxiredoxins in antioxidant defence and redox signaling. Subcell Biochem 44: 267-294, 2007.

3. Zhang B, Wang Y and Su Y: Peroxiredoxins, a novel target in cancer radiotherapy. Cancer Lett 286: 154-160, 2009.

4. Noh DY, Ahn SJ, Lee RA, Kim SW, Park IA and Chae HZ: Overexpression of peroxiredoxin in human breast cancer. Anticancer Res 21: 2085-2090, 2001.

5. Karihtala P, Mantyniemi A, Kang SW, Kinnula VL and Soini Y: Peroxiredoxins in breast carcinoma. Clin Cancer Res 9: 3418-3424, 2003.

6. Neumann CA, Krause DS, Carman CV, Das S, Dubey DP, Abraham JL, Bronson RT, Fujiwara Y, Orkin SH and Van Etten RA: Essential role for the peroxiredoxin Prdx1 in erythrocyte antioxidant defence and tumour suppression. Nature 424: 561-565, 2003.

7. Lee TH, Kim SU, Yu SL, Kim SH, Park DS, Moon HB, Dho SH, Kwon KS, Kwon HJ, Han YH, et al: Peroxiredoxin II is essential for sustaining life span of erythrocytes in mice. Blood 101: 5033-5038, 2003.

8. Wang X, Phelan SA, Forsman-Semb K, Taylor EF, Petros C, Brown A, Lerner CP and Paigen B: Mice with targeted mutation of peroxiredoxin 6 develop normally but are susceptible to oxidative stress. J Biol Chem 278: 25179-25190, 2003.

9. De Simoni S, Goemaere J and Knoops B: Silencing of peroxiredoxin 3 and peroxiredoxin 5 reveals the role of mitochondrial peroxiredoxins in the protection of human neuroblastoma SH-SY5Y cells toward MPP'. Neurosci Lett 433: 219-224, 2008.

10. Seo MS, Kang SW, Kim K, Baines IC, Lee TH and Rhee SG: Identification of a new type of mammalian peroxiredoxin that forms an intramolecular disulfide as a reaction intermediate. J Biol Chem 275: 20346-20354, 2000.

11. Kropotov AV, Grudinkin PS, Pleskach NM, Gavrilov BA, Tomilin NV and Zhivotovsky B: Downregulation of peroxiredoxin $\mathrm{V}$ stimulates formation of etoposide-induced double-strand DNA breaks. FEBS Lett 572: 75-79, 2004.

12. Sambrook J, Fritsch EF and Maniatis T: Molecular Cloning: A Laboratory Manual. Cold Spring Harbor Laboratory Press, New York, 1989.

13. Breitschopf H, Suchanek G, Gould RM, Colman DR and Lassmann H: In situ hybridization with digoxigenin-labeled probes: sensitive and reliable detection method applied to myelinating rat brain. Acta Neuropathol 84: 581-587, 1992.

14. Cha MK, Suh KH and Kim IH: Overexpression of peroxiredoxin I and thioredoxin1 in human breast carcinoma. J Exp Clin Cancer Res 28: 93, 2009.

15. Immenschuh S and Baumgart-Vogt E: Peroxiredoxins, oxidative stress, and cell proliferation. Antioxid Redox Signal 7: 768-777, 2005.

16. Chang TS, Jeong W, Choi SY, Yu S, Kang SW and Rhee SG: Regulation of peroxiredoxin I activity by Cdc2-mediated phosphorylation. J Biol Chem 277: 25370-25376, 2002.

17. Wagner E, Luche S, Penna L, Chevallet M, Van Dorsselaer A, Leize-Wagner E and Rabilloud T: A method for detection of overoxidation of cysteines: peroxiredoxins are oxidized in vivo at the active-site cysteine during oxidative stress. Biochem J 366: 777-785, 2002.

18. Lehtonen S: Localization and regulation of peroxiredoxins in human lung and lung diseases. Oulun Yliopisto, Oulu, 2005.

19. Moll R, Mitze M, Frixen UH and Birchmeier W: Differential loss of E-cadherin expression in infiltrating ductal and lobular breast carcinomas. Am J Pathol 143: 1731-1742, 1993.

20. Vos CB, Cleton-Jansen AM, Berx G, de Leeuw WJ, ter Haar NT, van Roy F, Cornelisse CJ, Peterse JL and van de Vijver MJ: E-cadherin inactivation in lobular carcinoma in situ of the breast: an early event in tumorigenesis. Br J Cancer 76: 1131-1133, 1997. 
21. Gown AM: Genogenic immunohistochemistry: a new era in diagnostic immunohistochemistry. Curr Diagn Pathol 8: 193-200, 2002.

22. Wood ZA, Poole LB and Karplus PA: Peroxiredoxin evolution and the regulation of hydrogen peroxide signaling. Science 300: 650-653, 2003.

23. Rhee SG, Jeong W, Chang TS and Woo HA: Sulfiredoxin, the cysteine sulfinic acid reductase specific to 2-Cys peroxiredoxin: its discovery, mechanism of action, and biological significance. Kidney Int Suppl 106: S3-S8, 2007.

24. Zhou Y, Kok KH, Chun AC, Wong CM, Wu HW, Lin MC, Fung PC, Kung H and Jin DY: Mouse peroxiredoxin V is a thioredoxin peroxidase that inhibits p53-induced apoptosis. Biochem Biophys Res Commun 268: 921-927, 2000.

25. Banmeyer I, Marchand C, Verhaeghe C, Vucic B, Rees JF and Knoops B: Overexpression of human peroxiredoxin 5 in subcellular compartments of Chinese hamster ovary cells: effects on cytotoxicity and DNA damage caused by peroxides. Free Radic Biol Med 36: 65-77, 2004

26. Kropotov A, Serikov V, Suh J, Smirnova A, Bashkirov V, Zhivotovsky B and Tomilin N: Constitutive expression of the human peroxiredoxin $\mathrm{V}$ gene contributes to protection of the genome from oxidative DNA lesions and to suppression of transcription of noncoding DNA. FEBS J 273: 2607-2617, 2006.

27. Awadelkarim KD, Arizzi C, Elamin EO, Hamad HM, De Blasio P, Mekki SO, Osman I, Biunno I, Elwali NE, Mariani-Costantini R, et al: Pathological, clinical and prognostic characteristics of breast cancer in Central Sudan versus Northern Italy: implications for breast cancer in Africa. Histopathology 52: 445-456, 2008.

28. Elgaili EM, Abuidris DO, Rahman M, Michalek AM and Mohammed SI: Breast cancer burden in central Sudan. Int J Womens Health 2: 77-82, 2010.

29. Khaled HM: Breast cancer at diagnosis in women of Africa and the Middle East. In: Breast Cancer in Women of African Descent. Williams CKO, Olopade OI and Falkson CI (eds). Springer, Dordrecht, The Netherlands, pp1975-2004, 2006.

30. Dressler LG, Berry DA, Broadwater G, Cowan D, Cox K, Griffin S, Miller A, Tse J, Novotny D, Persons DL, et al: Comparison of HER 2 status by fluorescence in situ hybridization and immunohistochemistry to predict benefit from dose escalation of adjuvant doxorubicin-based therapy in node-positive breast cancer patients. J Clin Oncol 23: 4287-4297, 2005.
31. Carlson RW and Stockdale FE: The clinical biology of breast cancer. Annu Rev Med 39: 453-464, 1988.

32. Ijaduola TG and Smith EB: Pattern of breast cancer among white-American, African-American, and nonimmigrant west-African women. J Natl Med Assoc 90: 547-551, 1998.

33. Masri MA, Abdel Seed NM, Fahal AH, Romano M, Baralle F, El Hassam AM and Ibrahim ME: Minor role for BRCA2 (exon11) and p53 (exon 5-9) among Sudanese breast cancer patients. Breast Cancer Res Treat 71: 145-147, 2002.

34. Awadelkarim KD, Aceto G, Veschi S, Elhaj A, Morgano A, Mohamedani AA, Eltayeb EA, Abuidris D, Di Gioacchino M, Battista P, et al: BRCA1 and BRCA2 status in a Central Sudanese series of breast cancer patients: interactions with genetic, ethnic and reproductive factors. Breast Cancer Res Treat 102: 189-199, 2007.

35. Mahfoudh W, Bouaouina N, Ahmed SB, Gabbouj S, Shan J, Mathew R, Uhrhammer N, Bignon YJ, Troudi W, Elgaaied AB, et al: Hereditary breast cancer in Middle Eastern and North African (MENA) populations: identification of novel, recurrent and founder BRCA1 mutations in the Tunisian population. Mol Biol Rep 39: 1037-1046, 2012.

36. Singh AK, Pandey A, Tewari M, Shukla HS and Pandey HP: Epigenetic silencing of BRCA1 gene associated with demographic and pathologic factors in sporadic breast cancer: a study of an Indian population. Eur J Cancer Prev 20: 478-483, 2011.

37. Konecny M, Milly M, Zavodna K, Weismanova E, Gregorova J, Mlkva I, Ilencikova D, Kausitz J and Bartosova Z: Comprehensive genetic characterization of hereditary breast/ovarian cancer families from Slovakia. Breast Cancer Res Treat 126: 119-130, 2011.

38. Zhu K,Hunter S,Payne-Wilks K, Sutcliffe C, Bentley C,Roland CL and Williams SM: Potential differences in breast cancer risk factors based on CYP1A1 MspI and African-American-specific genotypes. Ethn Dis 16: 207-215, 2006. 